part of Hyogo Prefecture in Japan. Approximately $0.34 \%$ of the residents of Kobe City were killed instantly and at least $2.4 \%$ were injured. Nearly $20 \%$ of them became temporarily homeless. In the stricken area, $9 \%$ of hospitals completely collapsed, and approximately $10 \%$ of hospitals lost their functions because of the disruption of lifelines and the shortage of manpower. Only $58 \%$ of the physicians, $44 \%$ of the nurses, $66 \%$ of technicians, and $31 \%$ of medical clerks were able to reach their facilities on that day. Damage of turnpikes and public roads made it difficult to transport them and the patients. The playgrounds regarded as temporary helipads were not usable because cars belonging to refugees occupied them immediately after that quake.

This presentation will detail the seismic problems.

Key Words: damages of hospitals; disaster; earthquake

\section{Casualties of the Earthquake Disaster}

Yukio Shimizu, MD; ${ }^{*}$ Yoshio Murayama, $M D$

${ }^{*}$ Director of Anesthesiology, Hakodate National Hospital, Hokkaido, Japan

A major earthquake kills and injures residents relative to its intensity. In Japan, a fairly large number of houses are wooden and vulnerable to the quake or fire. On 17 January, 1995, a major earthquake struck the southern part of Hyogo Prefecture. Approximately $0.34 \%$ of the residents were killed on that day. At least $2.4 \%$ of citizens were injured in Kobe City. In the most heavily stricken area of Kobe City, $0.87 \%$ of inhabitants were killed instantly and 3.4\% of them were injured.

Generally speaking, an earthquake strikes suddenly, and it is very difficult to immediately estimate the degree and the extent of the damages. In the future, if an earthquake of the magnitude 7 on the Richter scale occurs somewhere in Japan, we must be prepared at once for the emergency treatment of at least $3 \%$ of the residents of the affected area.

Key Words: casualties; disaster; earthquake; Kobe

\section{Principles of Evacuation of Shock Patients} in Intensive Care Medicine in the Siberia Region V. Slepubshkin; S. Vassiliev; O. Fomki; I. Galeev; A. Ivochkin; L. Koroll

Institute of General Reanimatology, Novokuznetsk Branch, Novokuznetsk, Russia

Characteristic factors that influence the evacuation of shock patients in the Siberia Region include:

1) low ambient air temperature for seven months of each year;

2) lack of good quality roads;

3) long distances; and

4) lack of proper ambulance and air transportation.

Due to these characteristics, the following measures are necessary in order to provide medical assistance in emergency situations:

1) the use of special isolating bandages on limbs of patients with shock and combined (frozen) traumas;
2) proper immobilization of limbs and vertebral column using vacuum frames and mattresses;

3) quick and stable compensation of deficits of volume of circulating blood volume (7.5/0) using a solutions of normal saline and colloid blood substitute (1:1) calculated as $5 \mathrm{mV} / \mathrm{kg}$ of body mass;

4) sufficient sedation and anesthesia (diprivan and analgesics of agonist-antagonist type);

5) prolonged forced ventilation of lungs with fans working from the mains and back-ups (Beer-33);

6) hemodynamic stabilization (solumedrol, dobutrex);

7) prevention of organ insufficiency (administration of neothone, 5-6 $\mathrm{g}$ of glucagon, $1 \mathrm{mg}$ aktovegin, $2 \mathrm{~g}$ of glucose);

8) monitoring of life providing functions $\left(\mathrm{SpO}_{2}\right.$, HR, AP, ECG); and

9) attendance of a resuscitation doctor, specially trained according to the program of intensive care medicine.

Key Words: ambulance; evacuation; hypothermia; resuscitation; shock; Siberia Region; transportation

\section{Action Cards Used to Link \\ Human Behavior and Disaster Planning}

Hans Suensson, RN

Department of Anesthesiology, Visby Hospital, Sweden

Background: Most disaster situations occur suddenly and without warning. With little information available, steps must be taken to build the organization of resources in a proper manner. Every participant must identify his/her starting position and know the direction for the first move. Using the Questions and Confusion Action Cards will provide good support for preparing the organization for the disaster.

Methods: In order that the common goal is made clear, everyone must have the same goal. The areas of responsibility must be balanced and the tasks divided-balance who is doing what and eliminate any duplication of jobs. Relevant factors as sectors, stations, and equipment should be coded and put into a computer program.

Results: Designing Action Cards with computer aid will provide a lot of complementary information. How staff will form the organization? What are the needs and level of qualifications in a specific sector or station? How are the sector teams manned in respect of what they are expected to do? The need of equipment can be of value to know in various parts of the organization.

Conclusion: Action Cards are superior to other methods to detail staff and save time. They will answer anyone's questions of "What to do?" and "Where to go?" and "With What?" in situations that often are foggy and turbid.

Key Words: action cards; disaster planning; human behavior 